\title{
Antoine D`Abbadie y el resurgir literario vasco en la segunda mitad del siglo XIX
}

\author{
PATRICIO URQUIZU
}

UNED 199I

Hojeemos el diccionario Robert de nombres propios buscando un escritor vasco. El resultado es decepcionante, el único nombre propio de la literatura vasca que hallamos es el de D'Abbadie, del que dice exactamente:

“Antoine Thompson d'Abbadie (Dublín, 1810-París, 1897). Después de una misión científica en Brasil en 1837 para estudiar las variaciones diurnas de la aguja imantada exploró Etiopía (18381848). Fue nombrado miembro titular de la Academia de Ciencias en 1867."

Pero como se ve no encontramos la menor referencia a la literatura vasca, por lo que intentaremos subsanar ese vacío del diccionario, hablando de las relaciones de D'Abbadie con el País y la lengua y literatura vascas.

Antoine nace en Dublín el 3 de enero de 1810, de padre vasco y madre irlandesa. Su padre Michel descendía de una antigua familia de abades laicos de Arrast, municipio cercano a Mauleón, capital de la provincia de La Soule en el País Vasco-Francés. Huyendo de la persecución revolucionaria fue a refugiarse a Irlanda donde se casó con Mlle Thompson.

Hacia 1820 vuelve a Francia y bajo el Imperio se afinca en Toulouse con sus hijos Antoine, Arnauld, Charles, Elise, Céline y Julienne.

Aquí se educó Antoine, y acabó brillantemente el bachillerato, iniciándose en la carrera de Derecho. Tuvo como camaradas a jóvenes genios que después serían insignes hombres de ciencias y letras como Granier de Cassagnac, Léonce de Lavergne y Duchartre, escritor, economista y botánico respectivamente. 
Ya para entonces Antoine practicaba sus aficiones poéticas en inglés y francés, y dominaba también el griego, el italiano y el euskara, su lengua paterna, cuyo amor les había transmitido el padre desde la infancia. Este se reveló. como después su hijo, un gran mecenas, ya que animó al parisino Fleury Lécluse, profesor de hebreo y griego de la facultad de Letras de Toulouse, y también de su hijo, a estudiar el euskara para lo que le pasó abundantes materiales, y posteriormente le pagó la edición de sus estudios que dieron como resultados el Manuel de la Langue Basque (Toulouse, 1826). Así también alentó al padre Darrigol' a que presentara sus trabajos sobre el euskara al premio Volney², siendo premiada su obra y también costeada por Michel.

En el año 1828 la familia se establece en París, rue St. Dominique. Antoine sigue los cursos de derecho y lee los Ensayos de Bacon. Hombre atlético y deportista nato, practicaba la esgrima, la gimnasia, la marcha y la natación, siendo admiradas sus hazañas en las playas de Biarritz el verano de 1827.

Durante los años 1830 y 1831 , sin abandonar el estudio del Derecho estudia Mineralogía y Geología inscribiéndose en la Facultad de Ciencias, avanzando en sus estudios de tal modo que el año 1836 será encargado por Arago, que junto con Alejandro Humboldt y Gauss se dedicaba al estudio del magnetismo terrestre, para hacer un viaje al Brasil, a la villa de Olinda, donde pasó dos meses haciendo más de dos mil observaciones astronómicas.

Durante el viaje en la bella fragata del Estado, llamada Andrómeda, se encontró con el príncipe Louis Napoleón, expulsado de Francia, y como había sido alumno de la célebre Mme Lenormand en París y era dado a hacer predicciones le dijo: Vd. está llamado a gobernar Francia, le concedo una cita en las Tuilleries. A lo que le contestó el príncipe: Si alguna vez llego al poder. queda Vd. invitado.

El año 1836 Antoine elabora junto con Joseph Augustin Chaho ${ }^{3}$, escritor de origen también suletino, discípulo de Charles Nodier en París y que siguiendo el consejo de éste había abandonado el arduo estudio de las leyes por la literatura y la política, una gramática vasca. Chaho ya había publicado algunas obras polémicas, y una de sus más famosas fue el Viaje a Navarra durante la

\footnotetext{
I JFAn PIERRI: DARRIGOI. (1790- I 829): Dissernation r ritique et apologétique sur la langue basque. Duhart-Fauvet Bayonne (1827): Analyse raisonnée du système grammatical de la langue basque, Prix Volney 1829

2 Constantin Francois de: Chasseboeuf (1757-1820): Comte de Volnev, lingüista eminente.

"En una carta de J. A. Chaho (BNP, MS, naf. 21.746, f. 374) se lee: "Nos deux noms figureront sur les premiers titre: Vous signerez votre travail A. Th. D'Abbadie de Navarre, et mon nom figurera sur le faux titre qui prendra mon premier chapitre (...). Eta adio, herritar maitia, zure adiskide biziko, gogoz eta bihotzez, Agosti Bassabürütarra."
} 
insurrección de los vascos (1830-1835) (A. Bertrand, París, 1836), que se tradujo rápidamente al castellano y al alemán, siendo esta última obra reseñada por Antoine en el Bulletin de la Société de Geographie, donde alaba el estilo fogoso y el patriotismo de su amigo.

Ese mismo año, pues, publican en colaboración Les études grammaticales sur la langue euskarienne (París, 1836). Los Prolegómenos de Antoine forman un breve estudio de 50 páginas, en las que menciona trabajos anteriores como los del historiador Oihenart, el notario Harriet, el jesuita Larramendi, el antropólogo Humboldt y el profesor Lécluse, corrigiendo algunas de sus observaciones. Así, por ejemplo, para Humboldt, los sufijos TASUN/-KERIA indicarían exceso y preferencia frente a carencia y ausencia, mientras que el significado que les asigna D'Abbadie es el de esencia por un lado y hábito por otro, opinión más ajustada a la realidad.

Menciona también a Franz Bopp ${ }^{4}$ conocido predecesor de la Gramática General Comparada, al que animó a dedicarse al estudio de la lengua vasca, y asimismo menciona las semejanzas del euskara con el hebreo, el lapón, el húngaro, el finés, el georgiano, y otras lenguas afines y americanas, concluyendo que la lengua cuyo sistema se acerca más al vasco es el quechua. Nos encontramos, pues, ante una obra que se halla plenamente imbuida del espíritu comparatista de la época.

$\mathrm{Al}$ año siguiente, en 1837, parte para Africa donde le espera su hermano Arnauld. Tras una estancia breve en El Cairo atraviesan Egipto y el mar Rojo para desembarcar en la isla de Massaonah, punto de partida habitual de las caravanas que se adentraban en Etiopía, y así ambos hermanos, uno dedicado a la política donde llegó a ser general, juez, diplomático y obtener el título de Ras Mikaël, y el otro a sus experimentos geográfico-físicos y aprendizaje de lenguas, pasaron doce años, llegando a lugares donde el europeo no había entrado anteriormente.

Antoine estudió los léxicos de una treintena de lenguas etiópicas y reunió más de cuarenta mil palabras, así como la colección de manuscritos etiópicos más rica del mundo, cuyo catálogo imprimió en 1859 . Redactó también un diccionario ammarina-francés superior a los anteriores, reunió monedas y medallas muy apreciadas por los numismáticos, a la vez que se interesaba por los datos más completos sobre las costumbres, los usos, derechos, la geografía y las lenguas de los países que visitó. Descalzo, con un turbante a la cabeza, practicando la medicina y avanzando más con las manos que con los pies. Es

\footnotetext{
${ }^{+}$Franz BoOP (1791-1867): autor del Sistema de conjugación del sánscrito en comparación con el del griego, latín. persa y germano (Frankfurt, 1816), y de la Grammaire comparée des langues indoeuropéennes (1866-1874).
} 
decir, llenando de regalos el trayecto, acompañado únicamente por sus criados aborígenes y el bastón como única arma ${ }^{5}$.

Mientras Antoine se hallaba con su hermano viajando por Africa, Chaho a mediados de siglo desplegó una actividad intelectual y política infatigable. Así, tras una serie de obras divulgativas sobre la historia y la lengua del País Vasco anuncia en el Trilby ${ }^{6}$, revista bayonesa de 1844 dedicada a las bellas artes, a la literatura, al teatro, y a los viajes, un cancionero vasco de cuya posesión se jactaba, ya que lo consideraba el más rico de los existentes.

El año 1844 Chaho creó su propio periódico, que tituló Ariel es decir, el ángel mensajero que gobierna la magia y la imaginación, y al que en sus diversas fases llamó: Le Courrier des Pyrénées, Le Courrier de Cantabrie et de Navarre, Le Courrier de Vasconie, y finalmente Le Républicaine de Vasconie. Incluso, el año 1848 creó un periódico enteramente en euskara, titulado Uscal Herrico Gaseta, que por desgracia no tuvo vida que sepamos, más allá del número 2. Adelantado, pues, en siglo y medio del que por fin se ha conseguido publicar a partir de diciembre de 1990.

Chaho era masón, y fue constante su pugna en la prensa contra las fuerzas conservadoras, llegando en las elecciones a ser nombrado miembro del Consejo Municipal de Bayona, comandante de la Guardia Nacional y así mismo miembro del Consejo General de los Bajos Pirineos, como partidario del partido republicano radical. Pero tras el golpe de estado de 1851 su periódico Ariel fue suprimido, y él expulsado al exilio.

Después de rehusársele la entrada en Bélgica pasará un año en Vitoria, escribiendo novelas y cartas, para volver a Bayona, bajo la promesa y la palabra de retirarse totalmente de la política. Compromiso que cumplió estrictamente, dedicado totalmente a su magna obra, el diccionario, que dejará inconcluso, en la mitad de la primera parte, tras llegar a la letra $\mathrm{L}$ de la parte neológica, ya que falto del aire de la lucha política, y rotos algunos de sus sueños y proyectos más predilectos, morirá en su buhardilla de Bayona a los cuarenta y siete años.

Pero así como se apaga esta estrella fugaz del romanticismo vasco, surge la figura duradera de su amigo de juventud, Antoine, que brillará con luz propia durante toda la segunda mitad del XIX.

En Ariel Chaho ya había publicado canciones sobre la revolución francesa, fábulas, canciones de amor que Garat, el tenor de la corte parisina entonaba en presencia de Marie Antoinette, poemas sobre las fiestas de Pamplona, escritas por Hiribarren (1845), etcétera.

\footnotetext{
5 Para más detalles: Gaston Darbolx (1907): Notice Hisforique sur Antoine d'Abbadie... (París).

' Fundado por Lespès, que era según Vinson, "Le soutien, l'espoir et le refuge de l'esprit libéral et indépendant", París, 1891 (Bibliografhie de la langue basque. Préface, xxxvij).
} 
Y será como hemos dicho Antoine, quien cogerá su testigo organizando el 9 de septiembre de 1851 un famoso partido de pelota, deporte que también él practicaba, en la localidad de Urrugne. Sobre este famoso partido se hicieron y publicaron unos pliegos sueltos, que el profesor Haritschelhar ${ }^{7}$ ya ha estudiado.

Es exactamente el año 1853, el año en que se inauguran Les Concours de Poésie. Anunciados en Le Messager de Bayonne el 9 de junio, tienen un tema de composición obligatorio: La Emigración a América. Las Américas, en plural como decimos los vascos, y su engañoso señuelo ya habían sido dos siglos y medio antes tratadas por el zumayano Baltasar de Etxabe ${ }^{8}$ en una obra publicada en México en 1607.

El primer poeta laureado fue el bardoztarra B. Celhabe. Sin embargo, este premio fue contestado por el poeta suletino Pierre Topet-Etchahun, el cual había presentado un poema titulado Montebideorat Juailiak (Los que se van a Montevideo). Al sentirse herido en su pundonor, ya que se le consideraba junto con Joanes Oxalde el mejor de los vates vascos del momento, escribirá unos versos contra el premiado en estos términos:

Celhabe Bardozeko, apez arnegata,

Apezek gure koblak zuri eman eta

Jarri izan zira koblarien aita.

(Cura renegado, Celhabe de Bardoze / habiéndote donado los curas mis coplas / has sido laureado como el padre de los poetas.)

A pesar de estas disensiones estas justas poéticas, que tienen su precedente en las celebradas en Toulouse ya en el año 1313, van a ser el caldo de cultivo de una pléyade de poetas y versificadores que serán la levadura del Renacimiento de la literatura vasca.

Desde 1853 hasta 1897, es decir, hasta su muerte Antoine D'Abbadie será el mecenas infatigable de las competiciones tanto deportivas como poéticas. Se iniciaba la gran fiesta con un partido de pelota, siendo los vencedores premiados con 500 francos, pero también se premiaba al mejor jugador, aunque fuera del bando de los perdedores, costumbre que incluso perdura hoy día. Después venía el coro que cantaba la composición del poeta premiado, y finalmente el concurso de improvisación por parejas, siendo sus temas impuestos del siguiente tenor: el aldeano y el ciudadano; el labrador y el artesano; el soldado y el desertor; el pescador y el cazador; el bailarín y el cantan-

7 Jeav HartTschelhar (1961): "1851, Urrugne 1961, Contribution à l'histoire de la Pelote", Gure Herria, Bayonne, 193.

${ }^{8}$ Baltasar de Echabe (1607): Discursos de la antigüedad de la lengua cámtabra bascongada, México. 
te; el soltero y el casado... Improvisaban uno contra otro hasta que la voz del presidente del jurado gritaba: ASKI! ( BBASTA!), y empezaba a enfrentarse otra nueva pareja hasta que sólo quedaban los dos vates de verbo más fácil y audaz.

Del año 1853 al 1863 estos juegos se celebraron en Urrugne, en la tierra de Labourt, aldea cercana al lugar donde se hizo construir D'Abbadie un castillo neogótico (1862-1870) con vistas al mar, según los planos de Viollet-le-duc, ejecutados por el arquitecto Dutkoit. Esta joya, cuyos salones están llenos de recuerdos de África y de refranes en diversas lenguas, está hoy abierta al turista. Entre los proverbios que mandó grabar en las diversas salas, se halla este árabe que dice: "La aguja viste a todo el mundo mientras ella se queda desnuda." Este etiópico: "La elocuencia del pobre son sus lágrimas." O éste en euskera: "Es suficiente un loco para arrojar una gran piedra a un pozo, pero son necesarios seis hombres prudentes para sacarla."

Los poetas laureados fueron, como he dicho, Celhabe (1853), Dussaut (1854), Larralde (1855-1859), Ithurbide (1857), Olhondo (1863) y Elizanburu $(1855,1858,1860,1862)$.

Vamos a detenernos en esta última figura, ya que precisamente este año celebramos el centenario de su muerte, pero antes vamos a hacer una cala en los años 57 y 58 .

1857 es un año clave en la historia de los estudios de lengua y literatura vasca, pues se publicaron durante el mismo dos obras fundamentales, una en París y otra en Berlín.

Charles August Friedrich Mahn" (Geller-Feld, 1802; y Steglitz, 1887), es un discípulo de la escuela positivista de Bopp y Schleicher, y seguidor de Humboldt en la cátedra de lenguas vivas de Berlín. Inventor, al parecer del término Romanische Philologie y gran estudioso de los trovadores, tras un viaje por el Pais Vasco se hizo con numerosos textos y libros antiguos que le sirvieron para redactar una gramática y una crestomatía, en la que no faltan las canciones populares.

Más interesante y completa es la obra de Francisque Michel (Lyon, 1809París, 1887), autor de múltiples obras entre las que destaca la edición de la versión original de la Chanson de Roland, que descubrió en la biblioteca de Oxford. Ya en 1847 había reeditado los Proverbios y Poesías de Arnaud Oihenart (1657), y durante los diez años siguientes se dedicó a recoger los

${ }^{9}$ C. A. F. Maнх (1857): Denkmaeler der baskische sprache..., Berlín. 
materiales que le sirvieron para su sintesis: Le Pays Basque, sa population, sa langue, ses moeurs, sa littérature et sa musique. Obra que sigue siendo aún hoy de consulta obligada para todo estudioso de la lengua y la literatura. El apartado dedicado a esta última sobrepasa las 300 páginas de letra menuda. Los estudios de literatura comparada que realiza dentro del campo de la poesía popular son de gran interés, aunque puedan pecar a veces de algo artificiales, pero sin duda son un ejemplo que debería imitarse con más frecuencia. Y así, al hablar de las canciones de Montevideo apunta que le recuerdan las baladas de Sir Walter Scott, a Casimir Delangue o a Taitien de Bouganville" ".

Evidentemente sus trabajos son el resultado de una extensa erudición y de una gran colaboración con autores del País. Por ejemplo, el capitán de aduanas, Jean Baptiste Duvoisin, le había hecho partícipe en 1855 de una serie de poemas de diversos géneros y varias épocas, que a su vez Michel envió a D’Abbadie, que a la sazón se hallaba en Londres".

El año 1858, como de costumbre el capitán Duvoisin hizo una reseña de las obras presentadas al concurso, en Le Courrier de Bayonne ${ }^{12}$, y entre otros comentarios al hablar de un poema de Joseph P(alassie) de Ezpeleta, se lamenta de que la magnífica inspiración que emerge en la séptima estrofa no se haya mantenido en el resto, pero augura a su autor un gran porvenir. Nos habla también del poema que ha merecido la mención de honorable, Belsunze y Abarka, de M. Heuty, pseudónimo tras el que se oculta Martín Hiribarren. Comenta además el poema titulado El roble y el laurel de un tal $\mathrm{M}$. Gasteluberri, considerando que contiene bellezas de primer orden, pero cuya ejecución hubiera exigido una docena de cantantes y toda una orquesta, recursos con los que no se podía contar en aquel momento, aparte de que no pudo ser premiada porque una de las condiciones del concurso era que se debía componer sobre una tonada tradicional, condición que no cumplía. El comentarista, que es a la vez autocrítico, pues se trata de una composición propia, piensa que esa exigencia, podía ser en muchos casos obstáculo para el libre vuelo del genio, que no se ajusta bien a las estrecheces de las reglas, por lo que no deberían ser éstas consideradas rigurosamente.

Más tarde, el año 1868 exactamente, al dirigirse al notario de Mauleón, Sallaberry ${ }^{13}$, folklorista que publicó dos años más tarde el primer cancionero vasco, le comenta que varias de las composiciones enviadas al concurso anual

\footnotetext{
10) F. Michli (1857): Le Pals Basque..., París, 340).

11 "Dans le série de poésie que vous ne faites connaître, je remarque un mélange d’antique et de moderne, de dialectes et de genres. Généralment les morccaux les plus récents méritent le moins d'attention [...]. Revenant à la poésie basque, je vous dirai que j’en ai fait un petit recuei] que j’ai prêté à M. A. d'Abbadie. M. A. d'Abbadie est actuellement à Londres. À son retour, je fairai un extrait que j’aurai le plaisir de vous envoyer", (Lettres adressées alu Capitain Duloisin, RIEV, XIX, 52-53).

12 Le Courrier de Bayone, joumal politique, littéraire, industriel et maritime, 1858-7/10-XI."' $\mathrm{F}$ 1.3 J:AN Sall.aberry (1870): Chants populaires du Pays Basque, Bayonne, Lamaignere.
} 
de poesía (ese año se celebraba en Sara), son desde el punto de vista poético superiores a todo lo producido anteriormente, y que tanto las obras premiadas como otras varias composiciones merecerían un trato mejor que el recibido hasta el momento, es decir, el del olvido, pues podrían llegar a formar una bella colección de poemas.

Como hemos dicho, uno de los poetas más relevantes de esta época es Jean Baptiste Elissamburu. Su novela corta, Piarres Adame publicada en 1888 también fue considerada por algunos críticos, como la obra maestra de la literatura vasca del XIX. Y sobre su poesía nos dice, el crítico Pedro Mourlane Michelena' $^{14}$, que aventajaba al guipuzcoano Agustín Iturriaga en limpidez, agilidad y brío, ... Elizamburu - al fin francés- sabe desde que dejó el Liceo, el arte de la composición. Evita la superfluidad pomposa y la redundancia. Tiende sin querer a la simetria y a la economía [...]. Si, Elizamburu hace en su caramillo volutas llenas de gracia. Será si se quiere anacreóntico, y habrá sabido resumir la vida en resignadas libaciones. Será a lo sumo un amoroso algo poeta, pero no es un poeta amoroso [...] canta al amor tranquilamente, con el vaso en la mano y la nariz un poco colorada.

Más agudo, el otro Michelena ${ }^{15}$ lo compara a su contemporáneo, el poeta gascón Justín Larrebat (1816-1869) por su fluidez y delicadeza, por su suave melancolía de corte lamartineano.

Poco a poco los concursos poéticos, a pesar de las críticas diversas de los jurados y azares varios, se fueron consolidando de modo que una vez acabada la segunda guerra carlista, se exportarán y servirán de modelo para el resto del País.

Duvoisin, crítico, comentarista y participante en los mismos, y que fue el primero en traducir y publicar la Biblia entera (Londres, 1859-1865) con la ayuda de Louis Lucien Bonaparte, con una finalidad puramente científica como confiesa en su correspondencia, será el asesor y mentor de Arturo Campión. Este navarro de pro funda en 1878 en Pamplona una revista de vida efímera titulada, Revista Euskara, que tiene entre sus proyectos, el cultivo de la literatura vasca, hoy olvidada o desconocida. El laburtano aconseja al navarro que al organizar las justas poéticas no imponga un tema determinado, sino que éste sea libre, ya que la pobreza de algunas piezas presentadas habría que achacarla precisamente a la falta de libertad que constreñía excesivamente la imaginación del poeta.

En la correspondencia de Duvoisin se pueden seguir paso a paso los avatares de dichos concursos, así como la reticencia de los vasco-franceses, sobre

\footnotetext{
14 Plibro Molrlane: Michlina (1919): "Los poetas en lengua vasca. La poesía vascongada en el siglo XIX", en Congreso de Estudios Vascos, Oñate, Bilbao, 626.

${ }^{15}$ Li is Michelena ( 1960): Historia de la Literatura Vasca, Minotauro, Madrid, 134.
} 
todo suletinos, a participar en los mismos, y sobre todo en el de Elizondo, al que asistirá el mismo Antoine d'Abbadie, y en el que será premiado un poeta vizcaino, escultor y pintor, Felipe Arrese Beitia de Ochandiano, por su poema La muerte del Euskera.

El año 1879 Duvoisin escribe a Manterola que la finalidad de los concursos era la de unir las provincias en un amor común por la lengua y la patria, cauterizar las divisiones internas trayendo la concordia, de modo que cada cual se dijera vasco y nada más.

Manterola crea en la Bella Easo, la Revista Euskal Erria, Revista Vascongada, cuyo primer número aparece el 15 de julio de 1880 presentando el siguiente programa de acción:

A recoger y transmitir los rasgos peculiares de la vida propia de estas siete provincias, que forman lo que podemos llamar la HEPTARQUÍA EUSKARA, a dar a conocer su antiquísima lengua, su especial literatura, sus originales cantos y traducciones, su historia, sus leyes y sus costumbres, reuniendo cuanto de más interés, inéditos, agotados ya o poco conocidos de nuestros antiguos y más distinguidos escritores, y buscando el apoyo de cuantos prestan hoy culto y nombre a las letras bascongadas, para hacer así de nuestra revista un verdadero Album, un archivo manual de curiosidades del país, se dirijirán todos nuestros esfuerzos ${ }^{16}$.

Y en esta labor se dieron la mano liberales y carlistas con un espíritu amplio y abierto como correspondía a la ciudad de San Sebastián, participando como dice expresamente Julio Caro Baroja: copia de escritores y poetas vascos que fueron liberales como mi abuelo ${ }^{17}$.

Participó en la primera década de la revista dirigida por el profesor Manterola, como hemos dicho un amplio grupo, del que vamos a destacar a Claudio Otaegui (Cegama, 1836 - Fuenterrabía, 1890).

Aunque más conocido como traductor oficial de los literarios fueristas, concuñado del príncipe Louis Lucien Bonaparte, forma junto con Indalecio Bizkarrondo "Bilintx" 18 y Serafín Baroja un trío que además de traducir poetas castellanos como Selgas, Campoamor o Bécquer, traduce a poetas de la denominada por Elías Amézaga ${ }^{19}$ Generación del Desconsuelo, que define en estos términos:

${ }^{16}$ Euskal Erria, Revista vascongada, San Sebastián, Baroja, 1880, número 1, 15 de julio.

17 Serafin Baroja (1988): Bertsoak, Pudente, Tormesko Lazarotxoa, Kontuak, Ed de Patri Urkizu, con prólogo de Julio Caro Baroja, San Sebastian, Txertoa.

${ }^{18}$ Indalecio Bizcarrondo, "Bilintx" (1961): Bertso ta lan guziak, Ed. de Antonio Zavala, San Sebastián, Auspoa, 12.

${ }^{19}$ Elías Amezaga, (1989): Euskadi: Al cruce de tres culturas Bilbao, 136. 
"La representación de este grupo, Manteli, Roure, Aretxavala, Perea, Francisca Sarasate, Alejandro Rivero, Iturribarría y otros va a hacerse entender de la mayoría. A dejar el divismo del vate cortesano, a ser humilde, transparente, permeable a la multitud, a inspirarse en temas llanos, en los que hasta entonces no se reparó, la niñez, la vejez, los débiles, la mujer, la paz de lo simple, el encanto de lo sencillo, la triste evocación de un pasado feliz, la esperanza de que vendrán tiempos mejores."

Así pues, la traducción de Roure ${ }^{21}$ hecha por Otaegui será comentada por Manterola en estos términos: Aquella preciosa composición, engendrada por el más intenso amor a la Euskalerria, ha alcanzado simpático eco en el país, y ha encontrado dentro de él un audaz intérprete que ha intentado con verdadero éxito, verterla a la lengua bascongada, sin hacerla perder por esto ni su grandeza, ni su interés, ni sus innumerables bellezas ${ }^{21}$.

Mas no se limitaron sus traducciones al campo castellano, ya que tradujo a Humboldt y también un poema de Mireio, obra de Federico Mistral (1859), poeta occitano premiado con el premio Nobel.

Claudio Otaegui fue premiado múltiples veces en la década de los ochenta, siendo a su vez promotor y colaborador de las iniciativas literarias del momento. Este es el retrato que nos hace de él su amigo Campión en la nota necrológica ${ }^{22}$ :

"Era Don Claudio de más que mediana estatura, vigoroso, recio de miembros, bastante obeso, de ojos vivos, en los que retozaba cierta jovialidad picaresca, la cual no excluía, sino antes bien se hermanaba, con la expresión bondadosa de su rostro. La sotabarba de pelo, á la moda yankee, subrayaba varonilmente su ancha y colorada cara, comunicábale el aspecto de un marino que, después de hecha la pacotilla y antes que la vejez llegue, se retira a saborear los encantos de la tierra y levanta su vivienda en las mismas orillas oceánicas, como para distraer con ternezas platónicas de miradas y saludos la pasión que los navegantes profesan al mar, émulo del cielo en cuanto á deprimir el ánimo con innumerables nostalgias."

De su producción de más de 7.700 versos distinguiríamos sus sonetos, que en euskara, en contra de la opinión generalizada sobre el espíritu lacónico de la lengua, son de 13 y 18 sílabas, en lo que se nos muestra como un adelan-

2) JOSÉ DE: ROLRE (Vitoria-Madrid, 1909), tras colaborar en revistas del País Vasco fue a Madrid donde cultivó casi todos los géneros, pero especialmente el cuento y la crónica. Fue redactor de El mundo, El Liberal, La correspondencia de España, Blanco y Negro, ABC... Son conocidos sus Cuentos Madrileños y los Cuadros del género.

21 Euskal Erria, T. II, 101.

22 Artliro Campion (1890): "Apuntes necrológicos, D. Claudio Otaegui”, Euskal Erria, XXII, 82. 
tado de los modernistas, ya que en éstos y en los poetas posteriores halla el soneto su más amplia libertad, fabricándolos de 20 sílabas, o como Machado con cuartetos que tienen rima independiente. También son de destacar sus poemas políticos así como los referentes a personajes históricos como Matxin Arzu (siglo XIV), Juan de Urbieta (siglo XVI) o Cosme Churruca (siglo XIX), cuyas hazañas rememora para rescatarlos del olvido de las historias oficiales.

Como venimos señalando los concursos literarios de la segunda mitad del siglo XIX, tanto en el País Vasco como en Cataluña $a^{23}$ supusieron la primera plataforma específica destinada a la organización y a la difusión cultural de la lengua, a la recuperación paulatina de su identidad, y planificaron la creación literaria, de la que resultó beneficiada en primer lugar la poesía y posteriormente la narrativa y el teatro.

Ya en el concurso literario organizado en San Sebastián en 1879 se premiaba a aquel autor que mejor escribiera sobre un aspecto parcial de alguna historia, leyenda o costumbre propia, digna de recuerdo.

Los escritores que se animaron y participaron con sus narraciones encontraron un sustancioso acervo de materiales en los cantos tradicionales, y las leyendas, incluidas las apócrifas, ya publicadas anteriormente por Chaho (1843), Goizueta (1851), Michel (1859), Araquistain (1866) y Cerquand (1875).

Los narradores postrománticos crean una nueva "historia" del País Vasco, que había sido ignorada en cuanto tal generalmente por los historiadores oficiales, y se abastecen de antepasados célebres, incluso se inventan la tradición vasca, utilizando la expresión de Jon Juaristi ${ }^{24}$.

Se parte de la leyenda de Aitor, padre de los vascos, alegoría que creó el iluminado Chaho, y que hoy subsiste como si de un personaje real se tratara en las canciones populares y en el nomenclátor juvenil de las nuevas generaciones. Y como señala Ana Toledo ${ }^{25}$, se atribuye el origen del pueblo vasco a Aitor, que vino del Este, de allá por los montes de Ararat en Armenia (Echegaray, 1882). Asentados en las estribaciones de los Pirineos los éuskaros soportan los ataques de los romanos que nunca llegaron a conquistar esas zonas montañosas (Campión, 1881; Arrúe, 1882). Pelean bravamente contra los francos en la época de la cristianización (López Alén, 1890; Aguirre, 1898), así como contra los visigodos y los moros (Echegaray, 1883; Arrúe, 1884), y al final de la Edad Media se enredan y enzarzan en sangrientas peleas fratricidas dirigidas por los parientes mayores, oñacinos y gamboínos (Echegaray, 1891).

Los personajes de las leyendas, así como posteriormente los de la primera novela histórica Auñamendiko Lorea (La Flor del Pirineo) (1898) de

23 JUaquín MOLas (1983): Els cent-cinquanta anys de la Renaixença, Barcelona.

${ }^{2+} \mathrm{JON} \mathrm{J}$ ( ARISTI (1987): El linaje de Aitor. La invención de la tradición vasca, Taurus, Madrid.

25 A^i Toltedo (1989): "El costumbrismo y la novela regional, Los orígenes de la novela vasca", II Congreso Mundial Vasaco, Hacia la literatura vasca, Castalia, Madrid, 227. 
Domingo Aguirre, o los del primer drama histórico Karmela (1886), de Pedro Harispe, así como los de las novelas de costumbres son la plasmación y encarnación de un ideario, la representación de las características y los afanes de un colectivo, el espejo de los vascos que se nos muestran en general como hombres rectos, leales, cristianos, fervorosos, amantes de la libertad y de la paz.

Sin embargo, la moda importada de Castilla en La Flor del Pirineo en la que deambulaban por doquier los Chilperico, Childelberto, Teodorico y otros personajes de su ralea no iba a tono con los gustos sencillos y elementales del lector en euskara, y el autor que reconocía su deuda para con Amaya o los vascos en el Siglo VIII, de Navarro Villoslada, la considerará un fracaso, y en consecuencia, abandonando los libros eruditos y de historia, tomará su cuaderno de notas y bajará a pasearse por el puerto a recoger directamente la vida y expresiones del mundo marinero, lo que transcrito casi literalmente se transformará en Kresala (Salitre), novela que tuvo mucha mayor aceptación y que incluso fue traducida al francés por P. Arburu.

De fruto tardío e intempestivo ha sido considerada la novela euskara, cuyo primer exponente, en la opinión de algunos críticos es La Flor del Pirineo, y es cierto lo del retraso en el tiempo. Sin embargo, si hablamos de narrativa "sensu lato" el panorama cambia. Nos cuenta uno de los mejores conocedores de la lengua y de los críticos literarios más perspicaces de este siglo, Pierre Lafitte ${ }^{26}$, que un día le preguntaron si existían novelas en euskara, a lo que contestó que teníamos algo mucho mejor: las vidas de santos. Y ciertamente éstas no se hallan exentas de imaginación, están construidas con rara habilidad, en estilo directo y poseen gran dramatismo.

Al margen de anécdotas, si consideramos como válida la clasificación que hace Ferreras de novelas históricas de aventuras contemporáneas podríamos incluir en este grupo la novela escrita por Jean Baptiste Dasconaguerre Les échos du pas de Roland, que en su versión de 1867 decía, haber sido traducida del euskara, pero al pedírsele el original se halló obligado a traducirla en equipo. Esta obra en euskara Atheka gaizeko oihartzunak, recoge las aventuras de un contrabandista de la primera guerra carlista, Ganix, que ayudó a la princesa de Beira a pasar la frontera y que se arruinó por defender la causa carlista, y es saludada por Pierre Lafitte como la primera novela vasca. Se trata de una narración llena de ritmo y viveza, en la que el autor según sus propias palabras, intenta pintar junto a la fisonomía del héroe, las costumbres y el carácter del país.

En lo que respecta al Teatro Moderno, es decir, el teatro ciudadano que surge en un contexto distinto al teatro popular folklórico de las farsas, tragicomedias de carnaval y pastorales suletinas merece apuntarse que es también en la segunda postguerra carlista cuando empieza a florecer. Exactamente, a par-

26 Pierre LafitTe (1941): Le Basque, et la littérature d'expression basque en Labourd, BasseNavarre et Soule. Aintzina, Bayonne, 58. 
tir de la obra del donostiarra Marcelino Soroa titulada, Iriyarena, que se estrenó en San Sebastián el 12 de mayo de 1878.

Fue tal el éxito de esta obrita que hasta su muerte (1902) no paró de escribir y dirigir piezas teatrales, de tono fundamentalmente cómico-satírico, siguiéndole en su labor un equipo de humoristas entre los que sobresalen Serafín Baroja, Victoriano Iraola, Toribio Alzaga y Pepe Artola.

El fin de siglo fue realmente de una gran vitalidad en lo que respecta a las letras vascas, tanto en Guipúzcoa como en Vizcaya, que siguió el ejemplo guipuzcoano bajo la batuta de Resurrección María de Azcue y de Sabino Arana. Pero fue también Antoine D'Abbadie quien introdujo el afán y apoyó las primeras Fiestas Euskaras que se celebraron en Durango el año 1886, donde se dieron cita gran número de escritores con obras de diversos géneros, y entre los que fue premiado precisamente el mencionado Marcelino Soroa.

Si tenemos en cuenta que dentro de la propaganda política nacionalista en función de su eficacia práctica, el teatro ocupaba el segundo lugar detrás de la prensa y delante del libro, no es de extrañar que tuviera el teatro durante el período 1876-1936 un gran desarrollo (más de quinientas obras).

Pero volvamos a D'Abbadie y finalicemos con él este breve recorrido por la literatura decimonónica. Como sabemos, fue Antoine un viajero impenitente, enamorado de los más diversos países y lenguas, tanto como de sus estudios astronómicos que nunca abandonó. Así el año 60 vino a Castilla (Briviesca), el 67 fue a Argel (Boussoul) para observar eclipses de sol, totales y parciales, y el 82 a Haití, para contemplar el paso de Venus sobre el sol.

Cuando murió el año 1897 se hallaba trabajando en la traducción del árabe al francés de un manuscrito titulado Futhuh el-Habach, que trataba de las conquistas y expediciones del Imán Ahmad a comienzos del siglo XVI.

El pueblo vasco, gracias a la iniciativa de la Société d'Ethnographie nationale et d'Art populaire, le brindó un gran homenaje en el congreso que se celebró del 15 al 22 de agosto de 1897, cuyos resultados se recogen en la obra La tradition au pays basque (1899) recientemente ${ }^{27}$ reeditada.

Eskualdunen aita (El padre de los vascos) era como le llamaban sus contemporáneos, pero incluso los vascos de hoy no lo tienen olvidado, ya que el año pasado, el pueblo suletino representó una pastoral dedicada a su vida y obra, basada en el libreto de Jean Luis Davant. De este modo Antoine D'Abbadie artífice del resurgir literario vasco de la segunda mitad del siglo XIX ha pasado por medio del arte de Tespis a ser uno de los héroes más admirados del País Vasco. Amor con amor se paga.

${ }^{27}$ La madition au Pasis Basque. Etmographic. Folk-lore. Art-popalaire. Histoire. Hagiographie (1899), (1982), Elkar, San Sebastián. 